\title{
Heparin-binding epidermal growth factor inhibits apoptosis in cisplatin-resistant pancreatic cancer cells via upregulation of EGFR and ERCC 1 expressions
}

\author{
Lingyang Zhou ${ }^{1 \star}$, Yuming Wang ${ }^{2}$, Shenghong Lan ${ }^{2}$, Mingfu Hu ${ }^{1}$, Lipeng Lu ${ }^{1}$ \\ ${ }^{1}$ Department of General Surgery. The First Affiliated Hospital of Wenzhou Medical University Yongjia Hospital, Wenzhou City \\ 325102, ${ }^{2}$ Department of General Surgery, The First Affiliated Hospital of Wenzhou Medical University, Wenzhou City 325000 , \\ China
}

*For correspondence: Email: zzuz0I@163.com

\begin{abstract}
Purpose: To investigate the influence of heparin-binding epidermal growth factor (HB-EGF) on apoptosis in cisplatin-resistant pancreatic cancer cells, as well as its mechanism of action.

Methods: Pancreatic cancer cisplatin-resistant cells (BXPC-3/CDDP) were transfected with HB-EGF small interfering RNA (siRNA). The cells were randomly assigned to four groups, namely, BXPC-3 group (group A), BXPC-3/CDDP group (group B), transfected group A (group Asi) and transfected group $B$ (group Bsi). Cell proliferation was determined using MTT assay, and the levels of expression of $H B-$ EGF, epidermal growth factor receptor (EGFR) and excision repair cross-complementation group 1 (ERCC 1) were determined using Western blotting. The extent of apoptosis was determined by flow cytometry.

Results: Cell proliferation was increased in group $B$, relative to group $A$, but was significantly decreased after transfection with HB-EGF siRNA ( $p<0.05)$. The half-maximal inhibitory concentration (IC50) of group Bsi was reduced, relative to group Asi $(p<0.05)$. The expression of HB-EGF was significantly upregulated in group $B$, relative to group $A(p<0.05)$. In contrast, HB-EGF siRNA transfection of the cells significantly down-regulated HB-EGF expression $(p<0.05)$. Early apoptosis was significantly higher in group $A$ than in groups $B$ and Bsi. Higher levels of apoptosis were seen in group Bsi, relative to group $B$ after inhibition of HB-EGF expression $(p<0.05)$.

Conclusion: These results indicate that HB-EGF is resistant to cisplatin, and it inhibits apoptosis in pancreatic cancer cells via the upregulation of EGFR and ERCC 1 expressions.
\end{abstract}

Keywords: Heparin-binding epidermal growth factor, Cisplatin resistance, Pancreatic cancer, Apoptosis, Proliferation, EGFR

This is an Open Access article that uses a fund-ing model which does not charge readers or their institutions for access and distributed under the terms of the Creative Commons Attribution License (http://creativecommons.org/licenses/by/4.0) and the Budapest Open Access Initiative (http://www.budapestopenaccessinitiative.org/read), which permit unrestricted use, distribution, and reproduction in any medium, provided the original work is properly credited.

Tropical Journal of Pharmaceutical Research is indexed by Science Citation Index (SciSearch), Scopus, International Pharmaceutical Abstract, Chemical Abstracts, Embase, Index Copernicus, EBSCO, African Index Medicus, JournalSeek, Journal Citation Reports/Science Edition, Directory of Open Access Journals (DOAJ), African Journal Online, Bioline International, Open-J-Gate and Pharmacy Abstracts

\section{INTRODUCTION}

Pancreatic cancer $(P C)$ is a highly malignant gastrointestinal tumor characterized by high mortality and poor prognosis. In the United States, less than $6 \%$ of PC patients survive beyond 5 years. In China, PC is ranked ninth in the hierarchy of malignant tumors [1]. Each year, more than 200,000 people worldwide die from PC, and the overall mortality keeps rising. Approximately $20 \%$ of patients diagnosed with PC go through surgical resection with a high 
probability of recurrence, and only $5 \%$ survive beyond 5 years [2].

Treatment strategies for PC include surgery, chemotherapy, radiation therapy and other comprehensive treatments. The disease is not easily detected at its early stage due to its high degree of malignancy. It is mostly diagnosed in the advanced stage, at which time radical surgery cannot be employed. Chemotherapy is an extremely important treatment for advanced PC. Cisplatin is usually used in PC chemotherapy, but its use is limited due to resistance. Reducing cisplatin resistance is an effective way to improve its chemotherapeutic effect in patients with PC.

Heparin-binding epidermal growth factor (HBEGF) is a peptide growth factor expressed in cultures of human macrophages, and is so named because of its strong affinity for heparin [3]. As an ubiquitous molecule, HB-EGF is present in various organs and tissues. Its expression is upregulated in various tumors. Studies have demonstrated a link between HBEGF and tumor progression since it accelerates cell cycle progression and proliferation [4]. Indeed, HB-EGF inhibits apoptosis via the activation of Ras/Raf/MAPK and AKT signaling pathways, and this phenomenon is evident in both tumor growth and drug resistance. Studies have also shown that HB-EGF can be used as a drug target in tumor chemotherapy and that it can reverse resistance associated with most chemotherapy drugs [5]. This study was carried out to investigate the effect of HB-EGF on apoptosis in cisplatin-resistant pancreatic cancer cells, and the underlying mechanism.

\section{EXPERIMENTAL}

\section{Materials}

Human PC cell line (BXPC-3) was provided by the Third Military Medical University Laboratory, while RPMI 1640 cell culture medium was purchased from Thermo Fisher Co., Ltd. (USA). Human HB-EGF gene-specific siRNA and nonspecific sequence siRNA were purchased from Sigma Co., Ltd. (USA). Cisplatin injection and MTT assay kit were products of Sigma-Aldrich (Germany), while lipofectamine reagent was obtained from Invitrogen (USA).

\section{Cell grouping}

Human PC cell line (BXPC-3) was used in this study. The pancreatic cancer cisplatin-resistant cells (BXPC-3/CDDP) were obtained by culturing some of the BXPC-3 cells in RPMI- 1640 medium containing increasing concentrations of cisplatin. Some of the BXPC-3 and BXPC-3/CDDP cells were transfected with HB-EGF siRNA. The cells were randomly assigned to four groups: BXPC-3 group (group A), BXPC-3/CDDP group (group B), transfected group A (group Asi), and transfected group B (group Bsi).

\section{Establishment of cisplatin-resistant PC cells (BXPC-3/CDDP)}

The parental BXPC-3 cells were maintained in RPMI-1640 medium to which were added FBS $(10 \%)$, as well as penicillin and streptomycin (each at a concentration of $100 \mu \mathrm{g} / \mathrm{mL}$ ), and incubated at $37^{\circ} \mathrm{C}$ in a humidified incubator with $5 \% \mathrm{CO}_{2}$. The culture medium was changed for fresh medium at intervals of $48-72$ h. At $80 \%$ confluency, trypsinization was applied to the cells. Cells in logarithmic growth phase were inoculated into RPMI-1640 medium containing increasing concentrations of cisplatin. The cells were incubated for 2 days, after which the cisplatin-containing supernatant was discarded and replaced with fresh medium. This procedure was repeated several times until cells that tolerated $1.0 \mu \mathrm{g} / \mathrm{mL}$ of cisplatin were obtained.

\section{Transfection of BXPC-3 and BXPC-3/CDDP cells with HB-EGF siRNA}

This was performed following Lipofectamine 2000 instructions. The BXPC-3 and BXPC$3 /$ CDDP cells were seeded into 96-well plates 24 $\mathrm{h}$ prior to being transfected. At $60-70 \%$ confluency, HB-EGF siRNA was transfected into the cells using liposomes, and the cells were incubated for 2 days.

\section{Western blotting}

This was carried out to determine the levels of EGFR, HB-EGF, and ERCC in the cells. The cells were lysed using chilled RIPA buffer for 180 $\mathrm{min}$. The cell lysate was rinsed two times in PBS, and then treated with $10 \mu \mathrm{g} / \mathrm{mLleupeptin}$, Nonidet P-40 (1 \%), Triton X-100 (0.1\%), $\mathrm{Na}_{2} \mathrm{PO}_{4}(30 \mathrm{mM})$ mixed with $1 \mathrm{nM}$ sodium orthovanadate, $2.5 \mathrm{mM}$ Tris- $\mathrm{HCl}, 100 \mathrm{mM} \mathrm{NaCl}$, and aprotinin for $45 \mathrm{~min}$ at $4{ }^{\circ} \mathrm{C}$. Thereafter, the cell suspension was subjected to centrifugation for $160 \mathrm{~s}$ at $12,000 \mathrm{~g}$ at $4{ }^{\circ} \mathrm{C}$.

Protein concentration of the supernatant was estimated with bicinchoninic acid (BCA) assay kit. A portion of total cell protein $(35 \mu \mathrm{g})$ from each sample was electrophoresed using $10 \%$ SDS-PAGE, followed by transfer onto a fixed PVDF membrane at $110 \mathrm{~V}$ and $90{ }^{\circ} \mathrm{C}$ for 120 min. Subsequently, skimmed milk powder (0.05 
$\%$ in Tris-buffered saline containing $0.2 \%$ Tween-20 (TBS-T) was added with gentle shaking at $37{ }^{\circ} \mathrm{C}$ and incubated to block nonspecific binding of the blot. Thereafter, the blot was subjected to incubation with primary antibodies of HB-EGF, EGFR, ERCC 1 and $\beta$ actin at a dilution of 1 to 200 at $4{ }^{\circ} \mathrm{C}$ overnight.

Then, the PVDF membrane was washed thrice with TBS-T and further subjected to incubation with HRP-linked goat anti-rabbit IgG secondary antibody (1:3000) for $60 \mathrm{~s}$ at room temperature. The blot was developed using an X-ray film. Grayscale analysis of the bands was performed using ImageJ analysis software (4.6.2). Respective protein expression levels were normalized to that of $\beta$-actin which was used as a standard reference.

\section{Assay of cell proliferation}

The cells were cultured in a 96-well plate at a density of $5 \times 10^{4}$ cells/well by adding FBS supplemented RPMI-1640 medium, and were incubated for $24 \mathrm{~h}$. Varied concentrations of cisplatin (up to $200 \mu \mathrm{g} / \mathrm{ml}$ ) were introduced, and the cells were subjected to incubation for $48 \mathrm{~h}$. Thereafter, MTT solution $(5 \mathrm{mg} / \mathrm{mL}, 20 \mu \mathrm{L})$ was put into each well, and the wells were incubated for $4 \mathrm{~h}$. Following medium removal, the resultant formazan crystals were solubilized in $150 \mu \mathrm{l}$ of DMSO, followed by agitation for $10 \mathrm{~min}$. Optical density of each sample was measured at $570 \mathrm{~nm}$ in a microplate reader. All experiments were done in triplicates and cell proliferation $(P)$ was calculated as shown in Equation 1.

$P(\%)=\{(1-A b s) / A b c\} 100$

where $A b s$ and $A b c$ are absorbance values of sample and control wells, respectively.

\section{Apoptosis assay}

Induction of apoptosis in the cells was determined using a flow cytometer. To each group of cells were added $500 \mu \mathrm{L}$ of digestive juice (a solution of $0.1 \%$ trypsin and $0.02 \%$ EDTA) until the cells appeared rounded and enlarged on microscopic examination. The cells were incubated for $72 \mathrm{~h}$, harvested and subsequently treated with HEPES binding buffer which contained propidium iodide $(\mathrm{PI})$ and Annexin V-FITC.

The treatment was carried out at room temperature for $20 \mathrm{~min}$, after which the cells were placed on a flow cytometer and read. The measurements were performed in triplicates and the mean was taken.

\section{Statistical analysis}

Data are expressed as mean \pm SEM, and statistical analysis was performed using SPSS, version 20.0. Two-group comparison was done using $t$-test. Statistical significance was fixed at $p$ $<0.05$ significant.

\section{RESULTS}

\section{Effect of treatments on cell proliferation}

There were only few viable cells in cisplatintreated wells. Cisplatin significantly and dosedependently reduced cell proliferation $(p<0.05)$. Cell proliferation was markedly increased in group $B$, when compared to group $A$, but was markedly decreased after transfection with HBEGF siRNA $(p<0.05$; Figure 1$)$.

Higher $\mathrm{IC}_{50}$ was seen in group $\mathrm{B}$ cells than in group $A$, but $I_{50}$ was significantly decreased after transfection $(p<0.05)$. However, $\mathrm{IC}_{50}$ was markedly lower in group Bsi than in group Asi ( $p$ $<0.05$; Table 1).

Table 1: Effect of cisplatin on cell proliferation

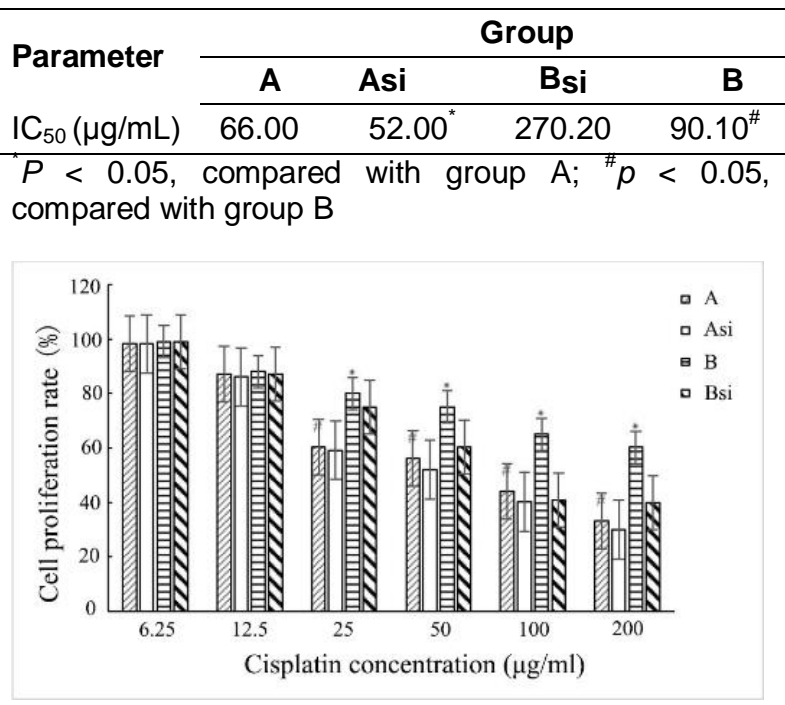

Figure 1: Effect of cisplatin on cell proliferation; ${ }^{\#} p<$ 0.05 , relative to group $B ;{ }^{*} p<0.05$, relative to $B$ si group

\section{Expression of HB-EGF}

Figure 2 shows that in group B, HB-EGF expression was markedly elevated, relative to that of group $A(p<0.05)$. However, when the cells were transfected with HB-EGF siRNA, HBEGF expression was markedly decreased $(p<$ 0.05 ). A significant reduction was seen in HBEGF expression in group Bsi, relative to group Asi $(p<0.05)$. 


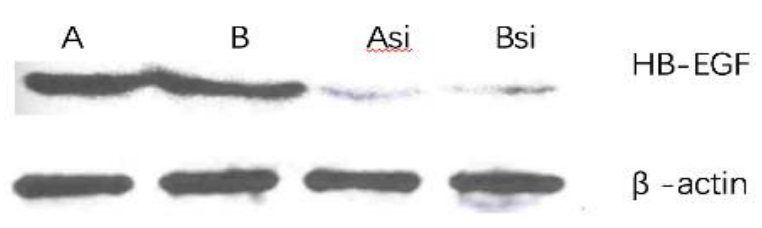

Figure 2: HB-EGF levels in the cells

\section{Expressions of EGFR and ERCC 1 proteins in cisplatin-resistant cells}

Figure 3 shows that the levels of expression of EGFR and ERCC1 were markedly less in group Bsi, when compared with group B $(p<0.05)$.

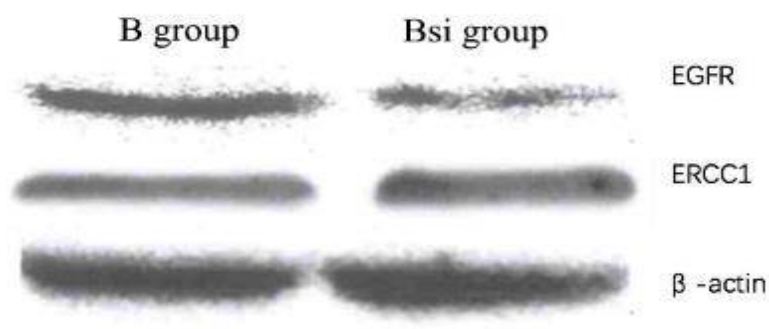

Figure 3: Degrees of protein expressions of EGFR and ERCC 1 in cisplatin-resistant cells

\section{Outcomes of flow cytometric analysis}

Early apoptosis was markedly increased in group A $(21.16 \pm 3.85 \%)$, relative to groups B $(0.47 \pm$ $0.12 \%)$ and Bsi (1.13 $\pm 0.08 \%)$. Apoptosis was also markedly higher in group Bsi than in group $B$ after inhibition of HB-EGF expression $(p<0.05$; Figure 4).
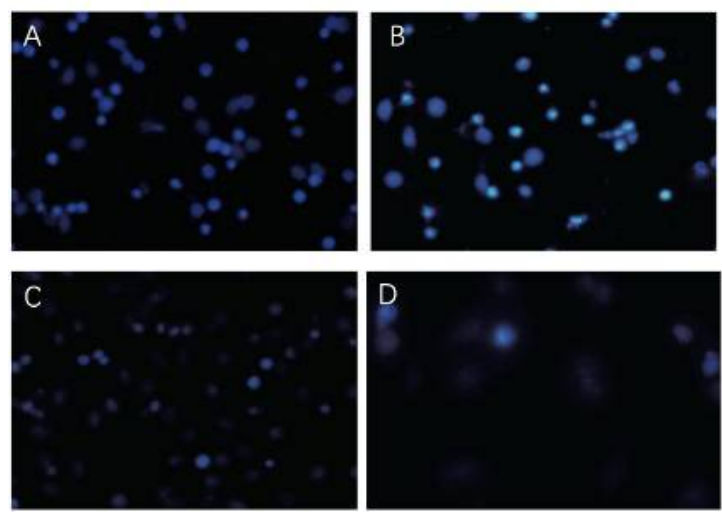

Figure 4: Morphology of cells under fluorescence microscopy (× 200). Groups Asi (A), A (B), Bsi (C), and $B(D)$

\section{DISCUSSION}

The current treatment for advanced PC is not very effective, and the mean survival is only 9 10 months [5]. The use of chemotherapy in the treatment of advanced PC can significantly prolong patients' survival. Due to structural similarities between cisplatin and its derivatives, its use as a chemotherapeutic agent is accompanied by serious resistance which limits its therapeutic effectiveness [6]. In order to overcome cisplatin resistance in PC treatment, it is important to find new targets.

Apoptosis, which is a programmed cell death, is regulated at the genetic level. Studies have shown that some anti-apoptotic proteins are involved in cisplatin resistance. It is known that HB-EGF, one of the seven ligands of EGFR, is highly expressed in a variety of tumor cells, and takes part in several physiological and pathological events.

In the present study, Western blotting showed that the expression of HB-EGF was markedly upregulated in group $B$, relative to group $A$. However, HB-EGF siRNA transfection downregulated HB-EGF expression. Moreover, HBEGF was expressed markedly less in Bsi group, when compared to group Asi. Thus, HB-EGF may be highly expressed in cisplatin-resistant cells. The $I_{50}$ was markedly higher in group $B$ than in group $A$, an indication that group $B$ cells were resistant to cisplatin. The $I_{50}$ of the cells was significantly decreased after their transfection with HB-EGF siRNA. Flow cytometric analysis showed that early apoptosis was markedly increased in group $A$, relative to groups Bsi and B. In addition, apoptosis was markedly accentuated in group Bsi, when compared with group B after inhibition of HBEGF expression.

Inhibition of HB-EGF expression increases the ability of cells to undergo apoptosis. Reduction in cell viability means increased apoptosis. In this study, there were only few viable cells in cisplatin-treated wells, and cisplatin significantly and dose-dependently reduced cell proliferation. Compared to group $\mathrm{A}$, there was a greater degree of cell proliferation in group $B$ but proliferation was markedly decreased after transfection with HB-EGF siRNA.

After activation by ligands, epidermal growth factor receptor (EGFR) initiates intracellular signal transduction, participates in cell migration, adhesion, proliferation, differentiation and apoptosis, and it is closely related to the degree of growth of malignant tumors [8]. As a receptor for HB-EGF, EGFR is highly expressed in PC cells. Excision repair cross-complementation group 1 (ERCC1) plays a key role in the repair of damaged human DNA [9]. Studies have suggested that high ERCC1 expression is implicated in poor clinical prognosis of cancers 
[10]. Overexpression of ERCC1 can rapidly repair damaged DNA arrested in G2/M phase of the cell cycle [11]. The expressions of EGFR and ERCC1 were decreased in group Bsi, relative to group B. It is likely that cisplatin resistance in PC cells is associated with EGFR and ERCC1 expressions.

Heparin-binding epidermal growth factor (HBEGF) may inhibit apoptosis of PC cells via the up-regulation of ERCC1 expression.

\section{CONCLUSION}

The results obtained in this study indicate that HB-EGF is resistant to cisplatin and inhibits death of PC cells through the upregulation of the expressions of EGFR and ERCC 1.

\section{DECLARATIONS}

\section{Conflict of interest}

No conflict of interest is associated with this work.

\section{Contribution of authors}

The authors aver that this study was carried out by those whose names appear in the manuscript. All liabilities appertaining to the manuscript content or claims arising therefrom are the sole responsibilities of the authors. All those whose names appear in this manuscript read and gave approval for its publication. Lingyang Zhou conceived and designed the study, Lingyang Zhou, Yuming Wang, Shenghong Lan, Mingfu $\mathrm{Hu}$, Lipeng Lu collected and analyzed the data. Lingyang Zhou wrote the manuscript.

\section{Open Access}

This is an Open Access article that uses a funding model which does not charge readers or their institutions for access and distributed under the terms of the Creative Commons Attribution License (http://creativecommons.org/licenses/by/ 4.0) and the Budapest Open Access Initiative (http://www.budapestopenaccessinitiative.org/rea d), which permit unrestricted use, distribution, and reproduction in any medium, provided the original work is properly credited.

\section{REFERENCES}

1. Mowbray NG, Griffith D, Hammoda M, Shingler G, Kambal A, Al-Sarireh B. A meta-analysis of the utility of the neutrophil-to-lymphocyte ratio in predicting survival after pancreatic cancer resection. HPB (Oxford) 2018; 20(5): 379-384.

2. Kushwaha R, Mishra J, Tripathi S, Raza W, Mandrah K, Roy SK, Bandyopadhyay S. Arsenic attenuates Heparinbinding EGF-like growth factor/EGFR signalling that promotes matrix-metalloprotease-9-dependent astrocyte damage in the developing rat brain. Toxicol Sci 2017; 162(2): 406-428.

3. Li CP, Lu MS, HB-EGF and its Role in Cancer. Progress Mod Biomed 2012; 12(23): 4566-4568+4559.

4. Inoue $Y$, Shimazawa $M$, Nakamura $S$, Takata $S$, Hashimoto $Y$, Izawa H, Masuda T, Tsuruma K, Sakaue $T$, Nakayama $H$, et al. Both Autocrine Signaling and Paracrine Signaling of HB-EGF Enhance Ocular Neovascularization. Arterioscler Thromb Vasc Biol 2018; 38(1): 174-185.

5. Beswick DM, Santa Maria C, Ayoub NF, Capasso R, Santa Maria PL. Epithelial separation theory for posttonsillectomy secondary hemorrhage: evidence in a mouse model and potential heparin-binding epidermal growth factor-like growth factor therapy. Eur Arch Otorhinolaryngol 2017; 275(2): 569-578.

6. Moghani-Ghoroghi F, Moshkdanian G, Sehat $M$, Nematollahi-Mahani SN, Ragerdi-Kashani I, Pasbakhsh P. Melatonin Pretreated Blastocysts along with Calcitonin Administration Improved Implantation by Upregulation of Heparin Binding-Epidermal Growth Factor Expression in Murine Endometrium. Cell J 2018; 19(4): 599-606.

7. Li H, Tang XH, Lu MS. Study on relationship between $H B-E G F$ and resistance of ovarian cancer to chemotherapy drug. Chin J Family Planning Gynecotokol 2016; 8(12): 15-20.

8. Séry $Q$, Rabé $M$, Oliver $L$, Vallette $F M$, Gratas $C$. $H B$ EGF is associated with DNA damage and Mcl-1 turnover in human glioma cell lines treated by Temozolomide. Biochem Biophys Res Commun 2017; 493(4): 1377-1383.

9. Chai WG, Wang GY, Xie SL, Wang M. Expression and clinical significance of ERCC1 and RRM1 in pancreatic cancer tissues. Chin J Gerontol 2013; 33(05): 10331034.

10. Hu WG, Wang CY, Liu T, Xiong JX, Yang ZY. Expression and significance of SHH, EGFR and PCNA proteins in pancreatic cancer tissues. J Cancer 2007; (09): 947951.

11. Heo J, Kim JG, Kim S, Kang H. Stat5 phosphorylation is responsible for the excessive potency of HB-EGF. J Cell Biochem 2017; 119(7): 5297-5307. 